\title{
Efektivitas Terapi Zikir terhadap Post Traumatic Stress Disorder (PTSD) pada Penyintas Tsunami Palu
}

\author{
Rannisa Muslaini ${ }^{1}$, Nanum Sofia ${ }^{2} *$ \\ 1,2 Prodi Psikologi, Universitas Islam Indonesia, Jl. Kaliurang km 14,5 Yogyakarta, Indonesia \\ *e-mail: nanumsofia@uii.ac.id
}

\begin{tabular}{lll}
\hline Abstract / Abstrak & & Keywords / Kata kunci \\
\cline { 1 - 3 } $\begin{array}{l}\text { This study aims to determine the effectivity of dzikr on post traumatic stress } \\
\text { disorder (PTSD) in Palu's tsunami survivors on the past 2018. This research }\end{array}$ & & $\begin{array}{l}\text { Dzikr training; } \\
\text { used experimental group and control group. Each groups consist of 5 }\end{array}$ \\
participants. Dzikr training were given to the experimental group while control \\
group were received the disaster education as placebo. The Impact of Event
\end{tabular}

\section{Pendahuluan}

Bencana alam yang dahsyat seringkali meninggalkan efek psikologis yang traumatik bagi para korban. Trauma pasca-bencana atau disebut sebagai Post Traumatic Stress Disorder (PTSD) bisa terjadi di manapun di dunia. Tidak terkecuali di Jepang (Matsu'ura, 2017), China (Gordon-Hollingsworth dkk, 2018), juga di Indonesia yang memiliki potensi bencana alam dahsyat yang tidak kalah dengan China. Dalam DSM-V (APA, 2017), PTSD termasuk kategori gangguan kecemasan. Gangguan tersebut meliputi rasa takut, tidak berdaya, dan ngeri. Hal itu akan membuat orang yang mengalami peristiwa merasa selalu mengingat atau membayangkan kejadian buruk tersebut baik melalui mimpi maupun kenangan, jika ingatan itu muncul secara tiba-tiba dan membuat seseorang merasakan kembali apa yang dialami pada peristiwa traumatik berarti orang itu mengalami flashback (kilas balik) (Durrand \& Barlow, 2006).

Beberapa karakteristik orang yang mengalami PTSD mengacu pada DSM-V ialah individu merasakan kembali kejadian tersebut, menghindari stimulus terkait trauma, meningkatnya gejala arousal, distress, dan gangguan tersebut terjadi secara terus-menerus dalam kurun waktu lebih dari satu bulan (APA, 2017); menghindari berbagai hal yang berhubungan dengan trauma yang dialaminya, tidak mampu mengingat aspek dari peristiwa traumatik, cenderung membatasi diri dan menurunnya respon emosional, hal tersebut akan membuat hubungan interpersonalnya menjadi terganggu (Rohmah, 2012); secara klinis merasakan over aroused, mudah kaget, 
dan emosi yang tidak stabil (cepat marah) (Durrand \& Barlow, 2006); merasakan emosi yang intens pada stimulus yang berkaitan dengan peristiwa traumatis, yang selanjutnya muncul intrusion (emosi, pikiran dan kenangan tentang peristiwa) hingga orang tersebut takut tidur karena khawatir bermimpi buruk. Selain itu ia akan merasakan gelisah, mudah terkejut, selalu tegang, cepat marah, sering sakit kepala, gangguan seksual, halusinasi, serta penurunan berat badan (Nirwana, 2012).

Beberapa faktor pencetus peristiwa traumatik diantaranya ialah bencana alam seperti gempa bumi (Ma dkk., 2020; Stratta dkk., 2016; Maya-Mondragon dkk., 2019); penyakit berat (Kazlauskiene \& Bulotiene, 2020); ditinggal orang yang dicintai, dan segala peristiwa tidak menyenangkan lainnya (Rohmah, 2012).

PTSD dapat terjadi pada siapa saja. Diantaranya pada pasien kanker (Kazlauskiene, \& Bulotiene, 2020); polisi (Potard dkk., 2018); veteran perang (Wingo dkk., 2017); bahkan tenaga medis sekalipun (Ma dkk., 2020), pada semua usia, misalnya pada anak-anak (Charnsil dkk., 2020); remaja, siswa, (Wojciechowski, 2019; Ayuningtyas, 2017; Xiao dkk., 2019); serta jenis kelamin, baik laki-laki maupun perempuan dengan prevalensi lebih banyak dialami oleh perempuan (Maya-Mondragon dkk., 2019). Meski demikian, tidak semua orang yang mengalami peristiwa traumatik dapat memicu distres psikologis dan kemudian memunculkan PTSD. Beberapa penelitian membuktikan bahwa terdapat individu-individu yang mampu menghindari PTSD, yaitu mereka yang resilien (Wingo dkk., 2017; Kukihara dkk., 2014); serta tangguh dan bermental kuat atau memiliki hardiness (Rohmah, 2012; Potard dkk., 2018).

Penelitian tentang PTSD di Indonesia kerapkali berhubungan dengan peristiwa bencana alam, misalnya tanah longsor (Endiyono \& Hidayah, 2018); erupsi Merapi (Kosvianti, 2012; Pratiwi dkk., 2012; Ulfa, 2013; Tentama, 2014); banjir bandang (Mulyadi, 2012) serta tsunami (Augustine, 2014). Hal tersebut tidak dapat dipungkiri karena Indonesia merupakan negara maritim yang sering mengalami gempa bumi disertai tsunami. Mengacu pada National Geographic Indonesia (2019), potensi gempa bumi dan tsunami di Indonesia cukup besar karena Indonesia dikelilingi oleh tiga lempeng tektonik yang terus bergerak, yakni lempeng IndoAustralia, lempeng Eurasia, dan lempeng Pasifik.

Gempa bumi dan tsunami terparah setelah peristiwa Aceh tahun 2004 ialah gempa dan tsunami Palu. Berdasarkan data dari Badan Meteorologi, Klimatologi, dan Geofisika (BMKG), gempa dan tsunami di Palu dan Donggala Sulawesi Tengah terjadi pada 28 September 2018 pukul 17:02:44 WIB berkekuatan 7.4 SR. Data yang dilansir kaltimtribunnews.com pada tanggal 22 oktober 2018 , tercatat 68.451 rumah rusak, 1.703 orang meninggal dunia, 1.309 orang hilang, 4.612 orang luka-luka, 223.751 orang mengungsi, dan kerap terjadi gempa susulan (Pardede, 2018).

Gempa bumi dan tsunami berkekuatan dahsyat tersebut dinilai memberikan dampak psikologis yang mendalam bagi para penyintas bencana karena tingkat kerusakan yang tinggi terutama potensi traumatik akibat mengalami bencana mengerikan. Untuk membuktikan adanya asumsi tersebut, peneliti melakukan studi pendahuluan dengan mewawancarai dua penyintas tsunami Palu. Penyintas pertama yang berinisial $\mathrm{R}$ (perempuan, pedagang), ia kehilangan suami, saudara, dan kerabat, serta kehilangan mata pencaharian, mengalami sulit tidur, sedih dan menangis saat menceritakan dirinya terombang-ambing di tengah laut seorang diri. Pada saat gempa, tanah di depannya terbelah dan ia terperosok masuk ke dalamnya, kemudian terseret air berwarna hitam setinggi pohon kelapa dan membawanya ke tengah laut hingga pingsan. Pasca-bencana, $\mathrm{R}$ memperbanyak aktivitas sehari-hari. Ia beralasan bahwa jika hanya berdiam diri akan membuat dirinya teringat kejadian tersebut dan menangis.

Penyintas tsunami kedua ialah M (lakilaki, nelayan). $\mathrm{M}$ menyatakan belum berani melaut lagi karena masih trauma, susah tidur, 
bingung dengan masa depannya karena tidak ada harta benda yang tersisa, menghindari laut, gelisah, merasa terus waspada, dan jantung berdebar jika mengingat peristiwa itu kembali. Meski sulit, $M$ berusaha mengambil hikmah dibalik kejadian yang menimpanya

Tsunami yang terjadi di Palu merupakan salah satu peristiwa traumatik yang jika tidak ditangani secara cepat dapat menimbulkan banyak dampak psikis maupun fisik. Oleh sebab itu, dibutuhkan penanganan segera untuk merehabilitasi baik fisik maupun psikis. Penanganan psikis/ psikologis, terutama dalam kasus PTSD sangat beragam. Ada medikasi/ farmakologi, psikoedukasi, trauma healing seperti play therapy (Nawangsih, 2014); terapi realitas (Masril, 2012); observed \& experiential Integration (OEI) (Tri dkk., 2014); maupun terapi yang menekankan pada aspek spiritual semisal Intervensi Spiritual Emotional Freedom Technique (Ulfa, 2013).

Dari beragam intervensi di atas, peneliti lebih merujuk pada budaya masyarakat Indonesia yang memiliki kultur kolektivis dan agamis dengan memilih penanganan psikologis yang religius terkait peristiwa tsunami tersebut guna mendekatkan jiwa yang terguncang akibat tsunami agar lebih dekat kepada ruh Ilahi melalui zikir. Dalam Q.S. Arra'ad ayat 28 Allah Swt. berfirman yang artinya: "Ingatlah, hanya dengan mengingat Allah (berzikir), hati menjadi tentram".

Berdasar pada firman Allah surah Arra'd tersebut, peneliti berasumsi bahwa kesedihan, kesulitan tidur, kebingungan, kewaspadaan yang tinggi, gelisah, menghindari peristiwa yang mirip, merupakan bentuk-bentuk kegoncangan jiwa yang dapat ditenangkan dengan mengingat pencipta. Alasan ini dikuatkan dengan berbagai penelitian yang sudah pernah dilakukan Benson (dalam Suwarningsih, 2019) bahwa spiritualitas merupakan aspek fundamental terpenting dalam menghadapi bencana. Oleh sebab itu, spiritualitas dapat dijadikan upaya pencegahan dari hal yang tidak diinginkan akibat dari peristiwa berduka seperti PTSD. Menurut Muhtarom (2016) untuk meningkatkan spiritualitas, seseorang harus membentuk pribadi yang sehat secara psikologis dan menyikapi permasalahan dalam hidup secara tepat sesuai dengan pandangan agama. Hal itu merupakan beberapa tujuan dari berzikir.

Zikir ialah hadirnya Allah Swt. di dalam hati dalam setiap urusan agama maupun dunia dengan cara mengulang-ulang asma Allah dengan hati dan lisan hingga terbebas dari kelalaian dan lupa (Al-Sakandari, 2018). AlWasithy menjelaskan bahwa zikir berarti meninggalkan bidang kealpaan dan memasuki bidang musyahadah (merasakan kehadiran Allah/ seakan-akan melihat Allah) mengalahkan rasa takut dan disertai kecintaan yang luar biasa (Hakim, 2015). Penjelasan tersebut selaras dengan Al-Ghazali, bahwa pada hakekatnya zikir ialah berkuasanya Allah di lubuk hati terdalam (al-lubb) dan memenuhinya dengan cahaya-Nya yang menyebar ke seluruh tubuh hingga menghilangkan rasa was-was (AlSakandari, 2018).

Penjelasan di atas didukung oleh penelitian-penelitian yang menerapkan konsep zikir dalam ranah pelatihan maupun terapi dalam usaha menenangkan jiwa atau menenteramkan hati, maupun meningkatkan kesehatan mental (Supenawinata, 2014; Ulfiah, 2018; Sulianti dkk., 2017). Beberapa penelitian yang membuktikan zikir memengaruhi ketenangan jiwa diantaranya ialah, pelatihan zikir pada pasien hipertensi secara nyata mampu meningkatkan ketenangan jiwa karena zikir merefleksikan kehidupan seseorang, mengingat, dan memohon ampun kepada Allah Swt. hingga membuat hati menjadi tenang (Kumala dkk., 2017); demikian juga pada jamaah majlis zikir, terdapat perubahan pada diri, hati, jiwa dan pikiran menjadi tenteram setelah para jamaah mengikuti terapi zikir (Fitri, 2013); demikian pula pada pengguna NAPZA, zikir mampu menenangkan jiwa mereka saat menjalani rehabilitasi dari ketidaktenangan dan ketakutan akan masa depan dan tidak diterima oleh lingkungan sosialnya suatu saat nanti (Kumala dkk., 2019).

Selain menenangkan jiwa atau menenteramkan hati, zikir terbukti 
meningkatkan kesehatan mental. Hal itu dibuktikan dengan penelitian yang dilakukan pada santri Pondok Pesantren Al-Hikmah Sukoharjo yang mana santri menjadi lebih mudah menerima materi, lebih mudah mengendalikan emosi, serta meningkatkan prestasi (Ikhsan dkk., 2017). Zikir berjamaah yang dilakukan para jamaah Kanzus Sholawat juga memiliki nilai terapeutik yang tinggi. Mereka yang mengamalkan zikir secara intens mengalami penyembuhan, peningkatan pemahaman spiritual serta bertambah optimis, lebih tenang, merasa rileks dan berkurangnya stres (Muhtarom, 2016); bahkan, pelatihan zikir memberikan efek yang besar terhadap kepuasan hidup, meningkatkan afek positif dan menurunkan afek negatif pada para istri infertil yang menjadi lebih ikhlas terhadap hidupnya, lebih mengingat Allah Swt., dan menyerahkan segala sesuatu kepada Allah Swt. (Wahyunita dkk., 2014).

Berdasarkan uraian di atas, zikir sebagai perlakuan terapeutik secara nyata berperan signifikan dalam banyak hal dan beragam konteks, tidak terkecuali pada masalah-masalah kecemasan, stres dan PTSD. Terlebih lagi masyarakat Indonesia yang memiliki basis kultural-spiritual-religius, pendekatan dan penanganan bernuansa agamis nampaknya secara signifikan lebih berperan positif dan menenangkan jiwa terutama zikir yang mencapai tahap musyahadah dan merasuk ke dalam al-lubb (inti hati yang paling dalam). Dengan demikian, peneliti mengajukan hipotesis bahwa zikir dapat menurunkan tingkat PTSD. Melalui penelitian eksperimental ini, peneliti ingin membuktikan bahwa pelatihan zikir efektif dalam menurunkan post traumatic stress disorder (PTSD) pada penyintas tsunami Palu.

\section{Metode}

\section{Desain Penelitian}

Penelitian ini menggunakan metode kuasi eksperimen yaitu pendekatan yang dilakukan untuk mengetahui efektivitas pelatihan zikir untuk menurunkan PTSD pada penyintas tsunami Palu 2018 dengan membandingkan skor antara dua kelompok (kelompok eksperimen dan kelompok kontrol), serta membandingkan skor yang diperoleh kedua kelompok sebelum dan sesudah intervensi. Penelitian ini menggunakan desain nonrandomized control group pretest-posttest design. Bentuk rancangan penelitian terangkum pada gambar 1.

\begin{tabular}{ccccc}
$\mathrm{KE}$ & $\mathrm{O}_{1}$ & $\mathrm{X}$ & $\mathrm{O}_{2}$ & $\mathrm{O}_{3}$ \\
\hline $\mathrm{KK}$ & $\mathrm{O}_{1}$ & & $\mathrm{O}_{2}$ & $\mathrm{O}_{3}$
\end{tabular}

Keterangan:

KE : Kelompok Eksperimen

KK : Kelompok Kontrol

$\mathrm{O}_{1} \quad$ : Pengukuran Pertama (pra-tes)

$\mathrm{O}_{2} \quad$ : Pengukuran Kedua (pasca-tes)

$\mathrm{X}$ : Perlakuan (Pelatihan zikir)

$\mathrm{O}_{3} \quad$ : Pengukuran Ketiga (Follow up)

Gambar 1. Rancangan eksperimen nonrandomized control group pretest-postest design

\section{Partisipan}

Partisipan penelitian ini adalah para penyintas tsunami Palu yang mengalami langsung peristiwa tsunami, berusia $25-55$ tahun, berpendidikan SD - SMA, dan tinggal di dalam barak pengungsian. Para penyintas ini diseleksi terlebih dahulu menggunakan skala PTSD. Partisipan yang mendapatkan skor hasil pra-tes PTSD berkategori sangat tinggi, tinggi, dan sedang, dimasukkan dalam penelitian ini. Dari hasil seleksi, diperoleh 10 partisipan yang kemudian dimasukkan 5 partisipan ke dalam kelompok kontrol dan 5 ke kelompok eksperimen.

\section{Instrumen Pengumpulan Data}

Pengumpulan data pada penelitian ini menggunakan skala untuk mengukur tingkat PTSD. Peneliti juga melakukan observasi dan wawancara guna melihat gambaran perilaku pasca-perlakuan untuk memperkaya data.

Skala PTSD diadaptasi dari skala Impact of Event Scale-Revised (IES-R) milik Weiss dan Marmar (1997). Skala tersebut terdiri dari 22 item, masing-masing item memiliki lima alternatif jawaban yaitu sangat sering, sering, 
kadang-kadang, hampir tidak pernah, dan tidak pernah. Pemberian skor untuk butir soal favorable adalah 4 untuk jawaban sangat sering, 3 untuk jawaban sering, 2 untuk jawaban kadang-kadang, 1 untuk jawaban hampir tidak pernah, dan 0 untuk jawaban tidak pernah. Skala PTSD yang digunakan ini terdiri dari 16 item dengan reliabilitas cronbach alpha sebesar .847 dengan tingkat validitas antar item yang bergerak mulai .300 hingga .700 .

\section{Prosedur penelitian}

Kedua kelompok sama-sama melakukan pengisian skala PTSD yang berupa pretest, kemudian diberikan intervensi yang berbeda yaitu kelompok eksperimen diberikan pelatihan zikir dan kelompok kontrol diberikan edukasi bencana alam. Pelatihan zikir diberikan selama 2 kali pertemuan, masing-masing berdurasi 120 menit dan edukasi bencana alam diberikan 1 kali pertemuan berdurasi 90 menit. Pada pertemuan terakhir kedua kelompok diberikan posttest (pasca-tes) dengan mengisi kembali skala IES-R dan 3 minggu setelahnya diberikan follow up (tindak lanjut) berupa pengisian skala IES-R dan wawancara.

Pelatihan zikir merupakan perlakuan (treatment) yang digunakan untuk menurunkan tingkat PTSD, menggunakan modul yang dimodifikasi dari Rusdi dkk. (2018). Pelatihan ini terdiri dari 16 sesi yang dibagi dalam dua kali pertemuan, yaitu sesi perkenalan, problematika hidup, edukasi terkait masalah, sharing inspirator, pentingnya zikir, refleksi, edukasi kalimah toyyibah, keutamaan zikir, mempraktikkan, serta terminasi. Pelatihan ini dipimpin oleh ustad yang ahli dalam pelatihan zikir. Setelah pelatihan, partisipan diukur tingkat PTSD-nya menggunakan skala IES-R sebanyak dua kali yaitu ketika pertemuan terakhir dan seminggu setelah pelaksanaan pelatihan tersebut.

\section{Teknik Analisis Data}

Data dianalisis menggunakan Statistical Package for Social Sciences (SPSS) 22.0 for Windows dengan uji hipotesis menggunakan teknik analisis statistik Anava Mixed Design
(Anava Campuran) untuk mengetahui efektivitas pelatihan antara kelompok eksperimen dan kelompok kontrol.

\section{Hasil}

\section{Uji Asumsi}

Pada hasil pra tes dan tindak lanjut, diperoleh nilai $\mathrm{p}=.200$ yang menunjukkan bahwa $\mathrm{p}>.5$ yang berarti skor PTSD pra-tes terdistribusi normal, demikian pula dengan hasil pasca-tes diperoleh nilai $\mathrm{p}=.197$ yang menunjukkan bahwa $\mathrm{p}>.05$ yang berarti normal.

Uji homogenitas berdasarkan Box's Test of Equality of Covariance Matrices menunjukkan bahwa nilai signifikansi homogenitas sebesar $\mathrm{p}=.354$ ( $\mathrm{p}>.05)$. Hal ini berarti variasi skor antara dua kelompok dapat dikatakan homogen.

\section{Uji Hipotesis}

Hipotesis dalam penelitian ini adalah ada pengaruh pelatihan zikir untuk menurunkan PTSD pada penyintas tsunami Palu 2018. Dari tabel Test of Within-Subjects Effect diperoleh hasil $\mathrm{F}=3.744$ dengan nilai signifikan $\mathrm{p}=.046$ $(\mathrm{p}<.05)$ yang berarti terdapat interaksi antara pra-pasca-follow up pada kelompok (eksperimen-kontrol). Interaksi tersebut menunjukkan bahwa terjadi perubahan skor pra menuju pasca dan tindak lanjut (Follow up) pada kedua kelompok berbeda secara signifikan. Dapat disimpulkan bahwa pelatihan zikir dapat menurunkan PTSD pada penyintas tsunami Palu 2018, sehingga hipotesis diterima.

Sumbangan efektif pelatihan zikir dalam menurunkan PTSD pada kelompok eksperimen dapat dilihat pada nilai partial eta squared sebesar .319 yang mengindikasikan bahwa pelatihan zikir dapat menurunkan PTSD sebesar $31.9 \%$. Hal tersebut dapat dilihat dari perbedaan skor mean pada penelitian ini antara kelompok eksperimen yang diberi pelatihan zikir dan kelompok kontrol yang diberi edukasi bencana alam sebagaimana disajikan pada gambar 2. 
Tabel 1

Hasil Uji Normalitas

\begin{tabular}{lll}
\hline \multicolumn{1}{c}{ PTSD } & P & Kategori \\
\hline Pra tes $\left(\mathrm{O}_{1}\right)$ & .200 & Normal \\
Pasca-tes $\left(\mathrm{O}_{2}\right)$ & .197 & Normal \\
Tindak lanjut $\left(\mathrm{O}_{3}\right)$ & .200 & Normal \\
\hline
\end{tabular}

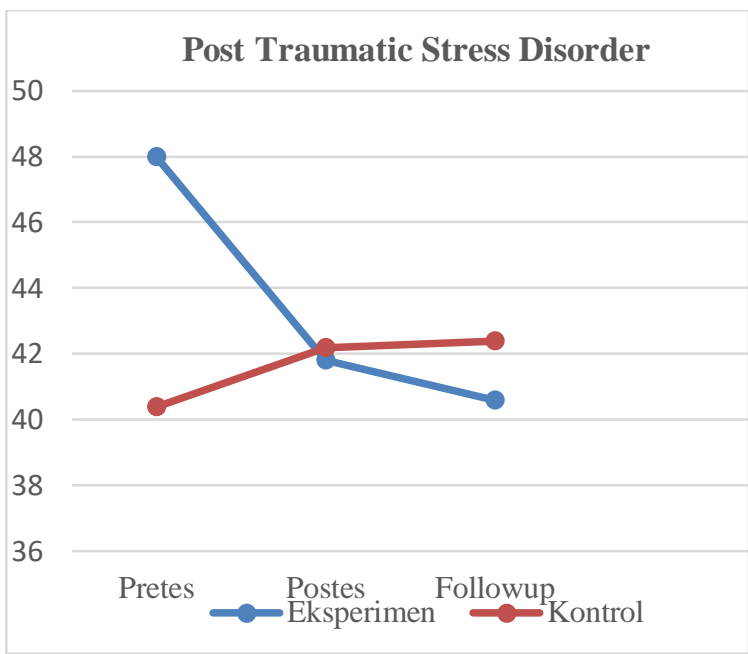

Gambar 2. Diagram pengukuran kelompok eksperimen dan kontrol

Berdasarkan grafik pada gambar 2, kelompok eksperimen selama tiga kali pengukuran mengalami penurunan tingkat PTSD yang signifikan saat pra-tes ke pasca-tes sebanyak 6.2 yaitu dari 48.00 menjadi 41.80 dan saat follow-up turun lagi sebesar 1.2 menjadi 40.60. Sementara itu, pada kelompok kontrol justru mengalami kenaikan tingkat PTSD. Pada pengukuran terakhir (follow up), skor mean kelompok kontrol lebih tinggi dibanding dengan kelompok eksperimen.

\section{Diskusi}

Hasil penelitian ini menunjukkan bahwa pelatihan zikir berpengaruh dalam menurunkan PTSD pada penyintas tsunami Palu 2018, dibuktikan dengan hasil uji hipotesis menggunakan anava mixed design, dengan nilai signifikansi $.046 \quad(\mathrm{P}<.05)$ yang berarti signifikan. Analisis partial eta squared menunjukkan bahwa pelatihan zikir berkontribusi secara efektif sebesar 31.9\%. Dalam penelitian ini ditemukan adanya perbedaan tingkat PTSD antara kelompok kontrol dan kelompok eksperimen, yaitu kelompok eksperimen (yang mendapatkan pelatihan zikir) mengalami penurunan tingkat PTSD dibanding kelompok kontrol (yang mendapatkan edukasi bencana alam).

Hasil penelitian ini mendukung penelitian Goodarzi dkk. (2011) yang meneliti korban gempa di Bam, Iran, terbukti bahwa orang yang menjadikan agama sebagai pedoman hidup memiliki PTSD yang lebih rendah. Ketika seseorang berzikir terus-menerus dengan penuh kekhusyukan maka akan terbentuk rasa kedekatan serta kecintaan kepada Rabb-nya. Syarif (2012) mengemukakan bahwa orang yang berzikir dengan khusyuk, secara psikologis akan merasakan keyakinan dan kehadiran Allah Swt. di sampingnya serta menganggap bahwa hidup di dunia ini tidak sendiri karena ada Dzat yang mampu mendengar segala kesusahan. Ketenteraman yang didapatkan dari zikir terbukti menimbulkan efek relaksasi bagi orang yang sedang menjalani penyembuhan trauma maupun penyakit.

Hasil penelitian ini juga selaras dengan penelitian Widyastuti dkk. (2019) yang melaporkan bahwa zikir secara efektif terbukti mengurangi kecemasan. Secara umum, berdasarkan hasil review literatur yang dilakukan Ross dkk. (2015), pendekatan terapeutik berlandaskan agama dan spiritualitas terbukti meningkatkan kesehatan dan optimisme.

Dalam pelaksanaan penelitian ini, sejak dilakukannya pra-tes hingga follow up masih sering terjadi gempa berskala kecil dan angin ribut. Kondisi tersebut ternyata meningkatkan trauma pada kelompok kontrol karena edukasi bencana yang diberikan sebagai perlakuan pada kelompok kontrol justru membuat mereka menjadi lebih tegang, bukan lebih relaks. Hal itu bisa dipahami karena edukasi bencana melatih orang agar menjadi lebih waspada (alert), bukan mengedukasi untuk mengatasi kecemasan atau kepanikan yang muncul saat bencana terjadi. Kondisi tersebut berbeda dengan kelompok eksperimen yang dibekali 
strategi preventif guna mengatasi kecemasan, kewaspadaan, penolakan, hingga flashback. Fenomena ini selaras dengan penelitian Slater dkk. (2016) bahwa orang yang menggunakan koping agama sebagai cara untuk beradaptasi dengan tantangan fisik, psikologis dan sosial akan memiliki tingkat PTSD yang lebih rendah dan tingkat emosi positif yang lebih tinggi.

Pada kelompok eksperimen, dari 5 partisipan hanya 1 partisipan yang mengalami peningkatan skor PTSD. Peningkatan tersebut terjadi pada setiap tahapan namun tidak signifikan karena kenaikan skor hanya 2 poin. Berdasarkan hasil wawancara lebih lanjut, $S$ (perempuan, 25 tahun) mengaku sangat takut ketika terjadi angin ribut dan sangat cemas mendengar isu-isu gempa susulan yang akan terjadi. Adapun partisipan lain relatif lebih tenang ketika dihadapkan dengan berbagai tekanan dan lebih memasrahkan kehidupannya kepada Allah Swt.

Selama pelatihan zikir, semua partisipan diminta untuk selalu merasakan nikmat yang diberikan Allah Swt. hingga tertanam rasa kepercayaan dan kecintaan kepada-Nya dengan cara bersikap ridho dalam menerima segala sesuatu yang terjadi pada dirinya dan yakin bahwa selalu ada hikmah dari setiap kejadian. Partisipan diminta melihat sisi positif dalam menyikapi bencana yang terjadi, bahwa hal ini merupakan teguran dari Allah Swt. agar umatnya lebih mendekatkan diri kepada-Nya. Mereka juga diberi motivasi dan semangat agar dapat segera bangkit dari keterpurukan. Hal ini yang membuat partisipan merasakan manfaat dari pelatihan zikir yang diberikan. Faktor lain yang memengaruhi penurunan skor PTSD disebabkan oleh kemampuan adaptasi partisipan setelah mengikuti zikir.

Berdasarkan hasil wawancara, para penyintas menceritakan pengalaman langsung kejadian traumatis berupa gempa dan tsunami, serta gempa susulan, angin kencang, kehilangan rumah serta harta benda, ditambah lagi ada beberapa wilayah terdampak yang masuk garis merah. Garis merah merupakan wilayah yang sudah tidak dapat ditempati kembali sehingga para penyintas ditempatkan di rumah yang diberikan oleh pemerintah setempat. Hal tersebut membuat para penyintas semakin stres menerima kenyataan yang ada.

Individu yang trauma, akan mengalami perasaan tidak tenang dan tidak nyaman. Menurut Dasril (2012) kondisi tersebut dapat diatasi dengan zikir atau mengingat Allah Swt. Ketika seseorang mengingat Allah maka sama halnya dengan menyandarkan diri kepada Allah Swt. Salah satu sifat yang dimiliki Allah yaitu Alwakil (tempat bersandar), sebagaimana disebutkan dalam kalimat zikir: "Hasbunallah wanikmal wakil nikmal maula wanikma nasir" (cukuplah Allah sebagai penolong kami, dan Allah adalah sebaik-baik pelindung).

Argumen di atas dibuktikan dengan hasil penelitian ini bahwa pasca-pelatihan zikir, partisipan lebih tenang ketika melihat stimulus yang berkaitan dengan peristiwa trauma, misalnya melihat laut atau rumah mereka yang hancur. Hal tersebut ditunjukkan oleh $\mathrm{N}$ salah satu penyintas yang sudah kembali mencari nafkah dengan menjual makanan dan minuman di pelabuhan. Saat $\mathrm{N}$ mengalami flashback tentang peristiwa traumatik, ia berzikir dan setelah itu merasa lebih tenang. $\mathrm{N}$ juga lebih mendekatkan diri kepada Allah Swt. Hal yang sama dilakukan oleh Y bahwa setelah pelatihan zikir, ia dan para penyintas lainnya yang mengikuti pelatihan menjadi lebih sering pergi ke mushola. Fenomena tersebut dapat dijelaskan melalui hasil penelitian Syarif (2012) bahwa zikir memiliki fungsi psikoterapeutik yang dapat dijadikan penyembuh, penguat spiritualitas, serta meningkatkan rasa percaya diri, dan optimisme.

Temuan pada penelitian ini ialah bahwa kelompok kontrol yang diberi edukasi bencana alam terkait tsunami justru mengalami peningkatan skor PTSD. Setiap partisipan mengalami peningkatan pada tahapan pengukuran yang berbeda-beda. Beberapa partisipan, yaitu NR, N, dan ST mengalami peningkatan skor PTSD pada tahapan pra-tes ke pasca-tes, sedangkan skor PTSD pada UN dan $\mathrm{S}$ meningkat pada tahapan pengukuran pascates ke follow up. Peningkatan skor PTSD terjadi pada kelompok kontrol juga dipengaruhi oleh 
sering terjadinya angin ribut dan gempa susulan berskala kecil yang membuat penyintas mengalami ketakutan. Hal tersebut dapat dimaklumi karena edukasi bencana hanya mengajarkan pengetahuan tentang kebencanaan dan cara menghadapi situasi tersebut, namun tidak mengajarkan upaya-upaya penanganan psikologis yang menenangkan jiwa saat menghadapi bencana.

\section{Simpulan}

Dapat disimpulkan bahwa pelatihan zikir secara nyata efektif menurunkan PTSD pada penyintas tsunami Palu 2018. Zikir terbukti mampu menurunkan tingkat PTSD baik PTSD tingkat sedang, tinggi, dan sangat tinggi. Sebaliknya, edukasi tentang bencana yang diberikan kepada kelompok kontrol justru meningkatkan tingkat PTSD karena edukasi bencana tidak memuat trauma healing atau penanganan menghadapi trauma yang muncul, melainkan hanya mengajarkan pengetahuan tentang kebencanaan dan cara menghadapi situasi tersebut sehingga menimbulkan efek psikologis yakni menjadi lebih waspada (alert). Zikir dapat dilakukan saat para penyintas akan atau sedang mengalami flashback, supaya tidak memicu terjadinya psychological arousal pada penyintas bencana. Dengan demikian, zikir dapat dijadikan sebagai upaya pencegahan maupun penanganan karena mampu memberikan ketenangan pada jiwa.

\section{Referensi}

Al-Sakandari, I. A. (2018). Dzikrullah bersama Ibnu Athaillah: Bagaimana sufi agung membimbing kita untuk mendekati sang Mahaagung. Lentera Hati.

APA. (2017). DSM 5-Update (Diagnostic and statistical manual of mental disorders, Fifth Edition). American Psychiantric Association Press.

Augustine, J. (2014). Predictors of posttraumatic growth among adult tsunami survivors: The role of employment, religion, and family attributes. Journal of Social Service Research, 40(4), 491-507. http://doi.org/10.1080/01488376.2014.894 368

Ayuningtyas, I. P. I. (2017). Penerapan strategi penanggulangan penanganan PTSD (post traumatic stress disorder) pada anak-anak dan remaja. Proceedings International Conference, pp. 47-56 1 $1^{\text {st }}$ ASEAN School Counselor Conference on Innovation and Creativity in Counseling: Promoting Equity through Guidance and Counseling http://ibks.abkin.org.

Charnsil, C., Narkpongphun, A., \& Chailangkarn, K. (2020). Post-traumatic stress disorder and related factors in students whose school burned down: Cohort study. Asian Journal of Psychiatry, 51 ,

102004. https://doi.org/10.1016/j.ajp.2020.102004

Dasril, D. (2017). Peranan zikir dalam menghadapi trauma yang dialami korban gempa. PROCEEDING IAIN Batusangkar, 1(1), 107-113.

Durand, V. M., \& Barlow, D. H. (2006). Intisari psikologi abnormal (Edisi IV). Pustaka Pelajar.

Endiyono, \& Hidayah, N. I. (2018). Gambaran post traumatic stress disorder korban bencana tanah longsor di Dusun Jemblung Kabupaten Banjarnegara. MEDISAINS: Jurnal Ilmiah Ilmu-ilmu Kesehatan, 16(3), 127-131. http://dx.doi.org/10.30595/medisains.v16i3 .3622

Fitri, N. (2013). Peranan zikir dalam terapi stres di majelis zikir As-Samawaat AlMaliki Puri Kembangan, Jakarta Barat (Skripsi tidak diterbitkan). UIN Syarif Hidayatullah, Fakultas Ilmu Dakwah dan Ilmu Komunikasi.

Gordon-Hollingsworth, A. T., Yao, N., Chen, H., Qian, M., \& Chen, S. (2018). Understanding the impact of natural disasters on psychological outcomes in youth from Mainland China: A metaanalysis of risk and protective factors for post-traumatic stress disorder symptoms. Journal of Child \& Adolescent Trauma, 
$11(2)$,

$205-226$.

https://doi.org/10.1007/s40653-015-0051-2

Hakim, M. L. (2015). Filosofi zikir. Cahaya Sufi.

Ikhsan, D., Fahmi, M. I., \& Mafan, A. (2017). Model psikoterapi zikir dalam meningkatkan kesehatan mental. academica: Journal of Multidiciplinary studies, 1(2). 273-283.

Kazlauskiene, J., \& Bulotiene, G., (2020). Prevalence of post-traumatic stress disorder among Lithuanian breast cancer patients and its risk factors. Journal of Psychosomatic Research, 131, 109939. https://doi.org/10.1016/j.jpsychores.2020.1 09939

Kosvianti, E. (2012). Hubungan antara tipe trauma dengan gejala PTSD pada siswa SDN pascaerupsi Merapi di Kecamatan Cangkringan Sleman Provinsi Daerah Istimewa Yogyakarta (Disertasi tidak diterbitkan). Universitas Gadjah Mada, Ilmu Kesehatan Masyarakat.

Kukihara, H., Yamawaki, N., Uchiyama, K., Arai, S., \& Horikawa, E. (2014). Trauma, depression, and resilience of earthquake/tsunami/nuclear disaster survivors of Hirono, Fukushima, Japan. Psychiatry and Clinical Neurosciences, 68(7), 524-533. https://doi.org/10.1111/pcn.12159

Kumala, O. D., Kusprayogi, Y., \& Nashori, F. (2017). Efektivitas pelatihan zikir dalam meningkatkan ketenangan jiwa pada lansia penderita hipertensi. Psympathic: Jurnal Ilmiah Psikologi, 4(1), 5566. https://doi.org/10.15575/psy.v4i1.1260

Kumala, O. D., Rusdi, A., \& Rumiani. (2019). Terapi zikir untuk meningkatkan ketenangan hati pada pengguna napza. Jurnal Intervensi Psikologi, 11(1), 43-54. http://dx.doi.org/10.20885/intervensipsikol ogi.vol11.iss1.art4

Ma, I. C., Chang, W. H., Wu, C. L., \& Lin, C. H. (2020). Risks of post-traumatic stress disorder among emergency medical technicians who responded to the 2016 Taiwan earthquake. Journal of the
Formosan Medical Association, 119(9), 1360-1371.

https://doi.org/10.1016/j.jfma.2019.11.021

Masril, M. (2012). Konseling post traumatic stress disorder dengan pendekatan "Terapi Realitas". Proceeding IAIN Batusangkar, 1(1), 184-192.

Matsu'ura, R. S. (2017). A short history of Japanese historical seismology: Past and the present. Geosci Lett., 4(3). https://doi.org/10.1186/s40562-017-0069-4

Maya-Mondragon, J., Roman, F. R. S., PalmaZarco, A., Aguilar-Soto, M., \& BorjaAburto, V. H. (2019). Prevalence of posttraumatic stress disorder and depression after the September $19^{\text {th }} 2017$ earthquake in Mexico. Medical Research, 50, 502508.

https://doi.org/10.1016/j.arcmed.2019.11.0 08

Muhtarom, A. (2016). Peningkatan spiritualitas melalui zikir berjamaah (Studi terhadap jamaah zikir Kanzus Sholawat kota Pekalongan, Jawa Tengah). 'Anil Islam: Jurnal Kebudayaan dan Ilmu Keislaman, 9(2), 247-267.

Mulyadi. (2012). Respon traumatik anak-anak korban banjir bandang di Wasior Papua Barat. Sosiohumaniora, 14(1), 12-23. http://dx.doi.org/10.24198/sosiohumaniora. v14i1.5475

National Geographic Indonesia. (2019). Indonesia rawan tsunami, manakah wilayah yang paling rentan?. National Geographic. https://nationalgeographic.gri d.id/read/131804119/indonesia-rawantsunami-manakah-wilayah-yang-palingrentan?page $=$ all.

Nawangsih, E. (2014). Play therapy untuk anakanak korban bencana alam yang mengalami trauma (post traumatic stress disorder/PTSD). Psympathic: Jurnal Ilmiah Psikologi, I(2), 164-178. http://dx.doi.org/10.15575/psy.v1i2.475

Nirwana, H. (2012). Konseling trauma pasca bencana. Ta'dib, 15(2). http://dx.doi.org/10.31958/jt.v15i2.224 
Pardede, D. (2018). Info terkini gempa Palu, korban tewas 2.256 orang dan masih hilang 1.309 orang dari Kaltim. Tribun News.

https://www.tribunnews.com/2018/10/21/i nfo-terkini-gempa-Palu-korban-tewas2256-orang-dan-masih-hilang-1309-orangberikut-rinciannya.

Pratiwi, C. A., Karini, S. M., \& Agustin, R. W. (2012). Perbedaan tingkat post traumatic stress disorder ditinjau dari bentuk dukungan emosi pada penyintas erupsi Merapi usia remaja dan dewasa di Sleman, Yogyakarta. Jurnal Wacana, 4(8). 87-115. https://doi.org/10.13057/wacana.v4i2.22

Potard, C., Madamet, A. I., Huart, I., El Hage, W., \& Courtois, R. (2018). Relationships between hardiness, exposure to traumatic events and PTSD symptoms among French police officers. European Journal of Trauma \& Dissociation. 2(4), 165-171. https://doi.org/10.1016/j.ejtd.2017.10.007

Rohmah, U. (2012). Resiliensi dan sabar sebagai respon pertahanan psikologis dalam menghadapi post-traumatic. Ilmu Dakwah: Academic Journal for Homiletic Studies, 6(2), $312-$ 330. https://doi.org/10.15575/idajhs.v6i2.3 40

Rusdi, A., Kumala, O. D., Ilmi, W. H., Triswidiastuty. S., \& Saniah, S. (2018). Pengembangan modul intervensi 3D-zikir. Pengembangan Modul Intervensi, Pusat Studi Psikologi Islam. Universitas Islam Indonesia.

Ross, J. J., Kennedy, G. A., \& Macnab, F. (2015). The effectiveness of spiritual/religious interventions in psychotherapy and counselling: A review of the recent literature. PACFA.

Slater, C. L., Bordenave, J., \& Boyer, B. A. (2016). Impact of spiritual and religious coping on PTSD. Dalam C. R. Martin, V. R. Preedy \& V. B. Patel (Eds.), Comprehensive guide to post-traumatic stress disorder. Springer, Cham. https://doi.org/10.1007/978-3-319-083599_49
Stratta, P., Sanita, P., Bonanni, R. L., Cataldo, S. D., Angelucci, A., Rossi, R., Origlia, N., Domenici, L., Carmassi, C., Piccinni, A., Dell'Osso, L., \& Rossi, A. (2016). Clinical correlates of plasma brain-derived neurotrophic factor in post-traumatic stress disorder spectrum after a natural disaster. Psychiatry Research, 244, 165-170. http://dx.doi.org/10.1016/j.psychres.2016.0 7.019

Syarif, M. (2012). Peran do'a dan zikir dalam menghadapi trauma yang dialami pasien di rumah sakit. Proceeding IAIN Batusangkar, 1(1), 147-155.

Sulianti, A., Yulianti, Y., Riswanda, R., Amalia, A. D., \& Anwar, R. (2017). Dhikr to manage epileptiform activity in a teenager with depressive disorder. IOP Conference Series: Material Science and Engineering, 288.

Supenawinata, A. (2014). Pengembangan potensi diri melalui metode zikir dan olah nafas (Penelitian padepokan perisai bathin dan silat laduni di kabupaten Bandung Barat). Psympathic: Jurnal Ilmiah Psikologi, 1(1), 22-31. https://doi.org/10.15575/psy.v1i1.464

Suwarningsih, Muhafilah, I., \& Herawati, T. M. (2019). Perubahan kondisi psikososial dan spiritual pada korban PTSD (post traumatic stress disorder) pasca banjir bandang di Kota Garut Jawa Barat. Jurnal Ilmiah Kesehatan, 11(1), 111. https://doi.org/10.37012/jik.v11i1.62

Tentama, F. (2014). Dukungan sosial dan posttraumatic stress disorder pada remaja penyintas Gunung Merapi. Jurnal Psikologi Undip, 13(2), 133138. https://doi.org/10.14710/jpu.13.2.133138

Tri, B. E. T. A. E., Anggadewi, A. T., \& Hadriami, E. (2014). Observed \& experiential integration (OEI) untuk menurunkan gejala stres pasca trauma (PTSD) pada perempuan korban kekerasan dalam rumah tangga (KDRT). 
PSIKODIMENSIA, 13(2). https://doi.org/1 $0.24167 /$ psiko.v13i2.261

Ulfa, E. (2013). Intervensi spiritual emotional freedom technique untuk menurunkan gangguan stres pasca trauma erupsi Gunung Merapi. Journal of Educational, Health and Community Psychology, 2(1), 38-57.

http://dx.doi.org/10.12928/jehcp.v2i1.3743

Ulfiah. (2018). Effectiveness of zikir therapy in improving religious commitment. Advance in Social Science, Educational and Humanities Research, 261. https://doi.org/10.2991/icie-18.2018.1

Wahyunita, D., Afiatin, T., \& Kumolohadi, R. R. (2014). Pengaruh pelatihan relaksasi zikir terhadap peningkatan kesejahteraan subjektif istri yang mengalami infertilitas. Jurnal Intervensi Psikologi, 6(2). 225-234. http://dx.doi.org/10.20885/intervensipsikol ogi.vol6.iss2.art7

Weiss, D. S., \& Marmar, C. R. (1997). The impact of event scale-revised. Dalam J. P. Wilson \& T. M. Keane (Eds.), Assessing psychological trauma and PTSD (hal. 399411). The Guilford Press.

Widyastuti, T., Hakim, M. A., \& Lilik, S. (2019). Terapi zikir sebagai intervensi untuk menurunkan kecemasan pada lansia. Gadjah Mada Journal of Professional Psychology (GamaJPP), 5(2). 149-157. https://doi.org/10.22146/gamajpp.13543

Wingo, A. P., Briscione, M., Norrholm, S, D., Jovanovic, T., McCullough, S. A., Skelton, K., \& Bradley, B. (2017). Psychological resilience is associated with more intact social functioning in veterans with posttraumatic stress disorder and depression. Psychiatry Research, 249, 206-211. http://dx.doi.org/10.1016/j.psychres.2017.0 1.02

Wojciechowski, T. W. (2019). Post-traumatic stress disorder and having antisocial peers in adolescence are risk factors for the development of antisocial personality disorder. Psychiatry Research, 274, 263268. https://doi.org/10.1016/j.psychres.2019.02. 053.

Xiao, Y., Liu, D., Liu, K., \& Jiang, X. (2019). Post-traumatic stress disorder and its risk factors in bereaved Tibetan adolescents 3 years after the 2010 Yushu earthquake, A cross-sectional study in China. Psychiatric Nursing, 33, 149-154. https://doi.org/10.1016/j.apnu.2018.11.010 
ZIKIR MENURUNKAN POST TRAUMATIC STRESS DISORDER (PTSD) PADA PENYINTAS TSUNAMI PALU 